\title{
BMJ Open Retrospective study of prognosis and relating factors of cardiac complications associated with electrical injuries at a single centre in Korea
}

\author{
Jae Hyuk Choi, ${ }^{1}$ Donghoon Han, ${ }^{\oplus}$ Si-Hyuck Kang, ${ }^{2}$ Chang-Hwan Yoon, ${ }^{2}$ \\ Jung Rae Cho, ${ }^{3}$ Dohern Kym ${ }^{\circ}$
}

To cite: Choi JH, Han D, Kang S-H, et al. Retrospective study of prognosis and relating factors of cardiac complications associated with electrical injuries at a single centre in Korea. BMJ Open 2019;9:e028741. doi:10.1136/ bmjopen-2018-028741

- Pre-publication history and additional material is published online only. To view please visit the journal online (http://dx.doi. org/10.1136/bmjopen-2018028741).

Received 26 December 2018 Revised 10 June 2019 Accepted 12 June 2019
Check for updates

(C) Author(s) (or their employer(s)) 2019. Re-use permitted under CC BY-NC. No commercial re-use. See rights and permissions. Published by BMJ.

For numbered affiliations see end of article.

Correspondence to Dr Donghoon Han; magnox@hallym.or.kr

\section{ABSTRACT}

Objectives To date, no research has investigated the association between cardiac complication and electrical injury; hence, we aimed to assess the consequences and relating factors of cardiac complications from electrical injuries in South Korea.

Design Retrospective single-centre study.

Participants 721 patients who had electrical injuryrelated admission during 2007-2017. An electronic medical record system was used to extract records of patients admitted for electrical injury treatment.

Results Cardiac complications included abnormal parameters of myocardial damage, abnormal regional wall motion detected via echocardiogram, dysrhythmia (eg, bradycardia, atrial flutter/fibrillation) and ventricular tachycardia or fibrillation. Overall, 107 patients (14.8\%) experienced cardiac complications. The average admission duration and intensive care unit stay duration were significantly longer in patients with cardiac complications than in those without them $(75.0 \pm 45.3$ vs $56.6 \pm 48.0$ days and $19.3 \pm 24.1$ vs $10.4 \pm 15.5$ days, respectively, $p<0.01$ for both). Of the total cardiac cases, $72.9 \%$ had Troponin I elevation, $3.7 \%$ had regional wall motion abnormality, and $5.6 \%$ had atrial flutter/fibrillation. Overall, seven patients from the cardiac complication group and three patients from the control group died $(p=0.01)$. All deaths occurred within 32 days, and the most common cause of death was septic shock. Total body surface area (TBSA) was only positively related factor to cardiac complications.

Conclusion This study is the first in South Korea to reveal that electrical accident patients with cardiac complications experience poorer in-hospital prognosis, and TBSA was the only risk factor of cardiac complications. And initial treatment for infection and inflammations could be important in electrical injury.

\section{INTRODUCTION}

Electrical injury represents one of the most severe public health problems in both developing and developed countries and occurs in both home and workplace settings. ${ }^{12}$ Electrical injuries can occur when an electrical current passes through the human body. ${ }^{3}$ Electrical injuries can be caused by a wide
Strengths and limitations of this study

- This article is the first domestic report of electrical injuries and cardiac complications related to electrical injuries.

- Our study documented that cardiac complications associated with poor prognosis and prolonged hospitalisation and that total body surface area were relevant factors of cardiac complications.

- This study showed that to control infection and inflammation at acute phase was important to manage the patients with major injury.

- This study is a single centre, retrospective design and did not include all aged patients, despite the fact that electrical injuries to children often occur with a low voltage in the home.

range of factors, and the spectrum of resulting injuries is similarly heterogeneous, ranging from small skin burns to life-threatening injury. ${ }^{134}$ The reported mortality associated with electrical injuries ranges from $1 \%$ to $9.1 \% .^{25}$ For example, in the United States, 4400 people are injured by electrical sources annually, and $9.1 \%$ of these individuals die. ${ }^{4}$ The cardiac complications related to electrical injuries include arrhythmias and myocardial tissue injuries, and the reported incidence of cardiac complications varies from $3 \%$ to $40 \% .^{236}$ Arrhythmias such as sinus tachycardia and ventricular premature beats are more common than myocardial injuries. ${ }^{36-8}$

In South Korea, Han et al reported that the incidence rate of electrical injury was $9.6 \% .^{9}$ However, domestic reports of electrical injuries remain lacking. Furthermore, cardiac complications of electrical injuries have never been reported in South Korea. The Hallym Burn Center at Hangang Sacred Heart Hospital is the largest burn centre in South Korea and serves as a regional referral 
centre. For this reason, burn patients come from all over the country to receive care at this centre. Therefore, we chose The Hallym Burn Center to conduct this singlecentre retrospective study, which examines the features of cardiac complications associated with electrical injury in South Korea.

\section{METHODS}

\section{Study population}

We extracted patient data from Hallym University Hangang Sacred Heart Hospital's electronic medical record system for patients who were admitted for electrical injury treatment between 2007 and 2017. We retrospectively examined all cases. Patients who were aged $\geq 19$ years and who were admitted owing to an electrical burn were considered for inclusion in this study. Patients with spark burns (eg, current does not enter or exit the body), patients aged $<18$ years, patients who were readmitted for treatment with a skin graft after their electrical injury, patients who underwent percutaneous coronary intervention or coronary artery bypass graft $(\mathrm{CABG})$ before their electrical injury or patients who were previously treated for arrhythmia were excluded. Documentation on the patients' baseline clinical characteristics, as well as their medication status at discharge were collected from their electronic medical records and reviewed. If there was no follow-up data within 6 months, we called the patients to explain the study protocol and obtained the patient's consent. At the same time, we confirmed whether the patients survived or not.

\section{Definitions of cardiac complications}

Cardiac complications were defined as (1) abnormal parameters of myocardial damage, such as a creatine kinase-MB isoenzyme and creatine kinase level fraction (CK-MB/CK) ratio of $>3$ or Troponin I level of $>0.15 \mathrm{ng}$ / $\mathrm{mL}$, (2) abnormal regional wall motion detected via echocardiogram, (3) newly detected dysrhythmias found via initial ECG, such as bradycardia, including sinus node dysfunction and atrioventricular block and paroxysmal atrial flutter/fibrillation and (4) sudden detected ventricular tachycardia or fibrillation after electrical injury. ${ }^{3810-14}$ Among the patients with electrical injuries, patients who did not meet the above definitions for cardiac complications were recruited for the control group (without cardiac injury/complications).

\section{Data analyses}

Differences between the cardiac complication group and the control group were analysed via Student's t-test. We analysed categorical variables with the $\chi^{2}$ test and Fisher's exact test. The observed rates of death and all-cause mortality were estimated using the Kaplan-Meier method. Group-wise differences were assessed with the log-rank test. To analyse correlation between total body surface area (TBSA) and haematologic, chemistry profile, Pearson test was performed. The potential risk factors imported into the logistic regression equation and analysed. $\mathrm{P}<0.05$ was considered statistically significant. The OR and $95 \%$ CI were calculated. Statistical analyses were performed using R programming V.3.5.1 (The R Foundation for Statistical Computing, Vienna, Austria; http:// www.R-project.org). A two-sided p value $<0.05$ was considered to be statistically significant.

\section{Patients and public involvement}

No patients were involved in developing the research question or the outcome measures, nor were they involved in planning the design, recruitment to and conduct of the study. However, we had plan to introduce the results of the research to the Korean society.

\section{RESULTS}

\section{Incidence and baseline characteristics}

From January 2007 to December 2017, 1261 of 22918 total burn-related patients were admitted due to electrical injuries $(5.5 \%)$. Of the 1261 patients, 331 were injured by spark burns and, according to exclusion criteria, were excluded from further analyses. Of the remaining 930 patients, we excluded 119 patient who were aged $<18$ years, 78 patients who were readmitted for treatment with a skin graft after electrical injury, eight who underwent percutaneous coronary intervention or CABG previously, three who were treated for arrhythmia prior to their electrical injury and one patient who declined to participate fully. Remaining 721 patients were included in the final analyses (figure 1). Annual number of patients with electrical injuries ranged from a minimum of 54 in 2014 to a maximum of 85 in 2010 (online supplementary appendix figure S1A). Their mean age was 43.2 years, with individuals in their 30s (25.6\%), 40s (38.6\%) and 50s (28.5\%) accounting for the majority of participants (online supplementary table S1 and figure S1B).

Overall, 702 of 721 patients $(97.4 \%)$ were male, and 363 patients $(50.3 \%)$ were non-smokers. A total of 513 patients $(71.2 \%)$ were injured by high-voltage shocks, and 365 patients $(50.6 \%)$ were initially admitted to the intensive care unit (ICU) (online supplementary appendix table S1). The most common path of electricity was from arm to arm (for further detail, see online supplementary appendix table S2).

\section{Cardiac complications in patients with electrical injuries}

Of the 721 patients examined, 107 (14.8\%) were classified into the cardiac complication group. The control groups included those who did not suffer any cardiac complications as a consequence of their electrical injury. There was no significant difference in the baseline characteristics between cardiac complication group and control group (table 1). Although the rate of patient injury from high voltage was not statistically different between the groups $(\mathrm{p}=0.12)$, the ICU admission rate was higher in the cardiac complication group than in the control group ( $74.8 \%$ vs $46.4 \%, \mathrm{p}<0.01$; table 2 ). Additionally, 


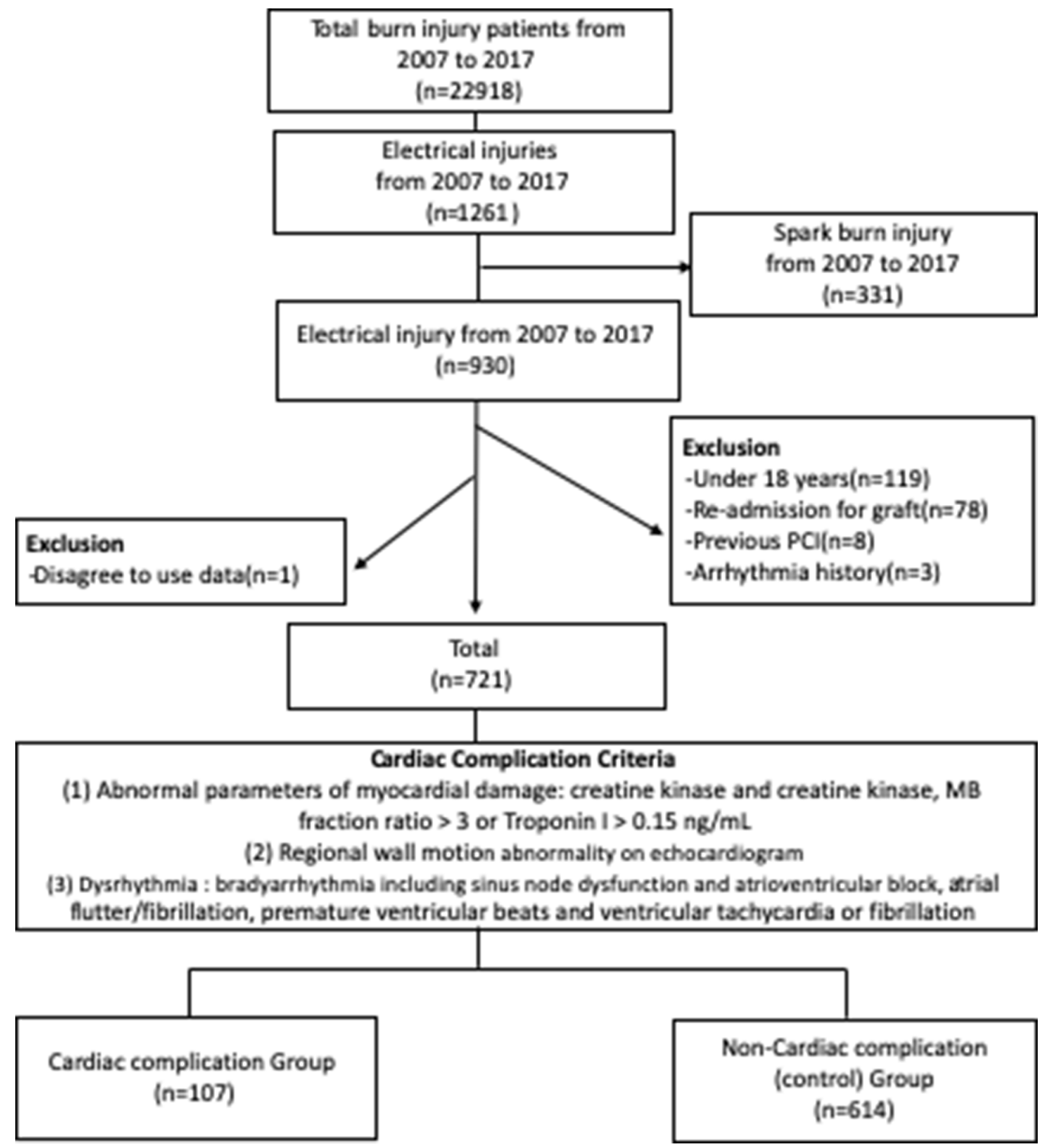

Figure 1 Study flowchart. PCl, percutaneous coronary intervention.

total body surface area (TBSA) was significantly higher in the cardiac complication group than in the control group $(24.4 \pm 19.3 \%$ vs $20.2 \pm 18.0 \%, p<0.01$; table 2$)$. The severity and relative number of grade 3 burns were significantly higher in the cardiac complication group than in the control group $(p<0.01)$. However, the rate of grade 4 burns was found to be higher in the control group than in the cardiac complication group $(8.4 \%$ vs $11.7 \%, \mathrm{p}<0.01$; table 2). Total admission duration and ICU stay duration were significantly longer in the cardiac complication group than in the control group (figure $2 \mathrm{~A}, \mathrm{~B}, \mathrm{p}<0.01$ ). The rates of surgical interventions including amputation, escharotomy, fasciotomy and skin grafts were greater in the cardiac complication group than in the control group. Additionally, the cardiac complication group underwent more than three times the number of surgeries received by the control group, although this difference was not statistically significant (table 2).
Eighty patients $(74.8 \%)$ in the cardiac complications group showed Troponin I elevation on their first day of treatment. A regional wall motion abnormality was detected in four patients via echocardiogram. However, cardiac markers for these patients were within the normal range. Atrial fibrillation was observed in five patients, and atrial flutter was observed in one patient. Atrial fibrillation and flutter were detected for the first time in five patients and one patient, respectively. However, no one detected bradycardia in ECG (online supplementary appendix table S3).

\section{Death in patients with electrical injury}

Of the total 721 patients examined, 10 (1.4\%) patients died (figure 2C). All deaths occurred within 32 days of treatment (figure 2C, online supplementary appendix table S4). Of the total deaths, seven patients experienced cardiac complications, four patients died due to septic shock, and two patients died as a result of burn shock. 


\begin{tabular}{|c|c|c|}
\hline Characteristics & $\begin{array}{l}\text { Cardiac injury, } \\
N=107\end{array}$ & Control, $\mathrm{N}=614$ \\
\hline Age & $45.0 \pm 11.1$ & $42.9 \pm 10.3$ \\
\hline Men, n (\%) & 103 (96.3) & $599(97.6)$ \\
\hline Body weight (kg) & $69.6 \pm 9.1 \mathrm{~kg}$ & $69.3 \pm 10.6$ \\
\hline Height (cm) & $172 \pm 6.4$ & $171 \pm 6.1$ \\
\hline BMI $\left(k g / m^{2}\right)$ & $23.5 \pm 2.7$ & $23.7 \pm 3.1$ \\
\hline \multicolumn{3}{|l|}{ Smoking, n (\%) } \\
\hline Never smoking & $58(54.2)$ & 305 (49.7) \\
\hline Smoking & $49(45.8)$ & $309(50.3)$ \\
\hline HTN, n (\%) & $12(11.2)$ & 61 (9.9) \\
\hline CAD, n (\%) & $1(0.9)$ & $4(0.7)$ \\
\hline $\mathrm{DM}, \mathrm{n}(\%)$ & $6(5.6)$ & $24(3.9)$ \\
\hline $\begin{array}{l}\text { CKD or ESRD, } n \\
(\%)\end{array}$ & $0(0)$ & $1(0.2)$ \\
\hline Aspirin, n (\%) & $1(0.9)$ & $14(2.3)$ \\
\hline ACEi or ARB, n (\%) & $6(5.6)$ & $37(6.0)$ \\
\hline B-blocker, n (\%) & $0(0)$ & $11(1.8)$ \\
\hline Statin, n (\%) & $0(0)$ & $11(1.8)$ \\
\hline Metformin, n (\%) & $4(3.78)$ & $13(2.1)$ \\
\hline
\end{tabular}

$\mathrm{ACEi}$, angiotensin-converting enzyme inhibitors; ARBs, angiotensin receptor blockers; $\mathrm{BMI}$, body mass index; $\mathrm{CAD}$, coronary artery disease; CKD, chronic kidney disease; DM, diabetes mellitus; ESRD, end-stage renal disease; HTN, hypertension.

One patient experienced sudden cardiac arrest while being transported to the operating room.

In the cardiac complication group, significant differences were not seen in the survival rate in subgroup analysis of TBSA $(p=0.07)$ and voltage difference $(p=0.38)$, even though the major burn group and high voltage group were reduced (online supplementary appendix figure S2).

\section{Risk factors of cardiac complications}

We also examined potential risk factors for cardiac complications related to electrical injury. Patient characteristics, such as body mass index (BMI), smoking history, hypertension and diabetes were associated with cardiac complications; however, the associations were not statistically significant. In addition, the injury-related factors of voltage, TBSA, left-side of entrance and exit and entrance and exit via arm showed positive associations, but only TBSA was significantly associated with cardiac complication. (figure 3)

\section{Analysis of correlation factors}

We analysed the relationships between factors, such as high voltage, admission duration and ICU duration, TBSA, white blood cell (WBC) count, erythrocyte sedimentation ratio, $\mathrm{C}$ reactive protein, $\mathrm{CK}, \mathrm{CK}-\mathrm{MB}$ isoenzyme, CK/CK-MB ratio, Troponin I and survival duration in the patients with electrical injuries. TBSA was positively
Table 2 Comparison of burn and admission characteristics between the cardiac complication and control groups

\begin{tabular}{|c|c|c|c|}
\hline Variables & $\begin{array}{l}\text { Cardiac } \\
\text { complication } \\
(n=107)\end{array}$ & $\begin{array}{l}\text { Control } \\
(n=614)\end{array}$ & $p$ value \\
\hline $\begin{array}{l}\text { High voltage, } n \\
(\%)\end{array}$ & 87 (81.3) & $426(69.4)$ & 0.12 \\
\hline $\begin{array}{l}\text { ICU admission, } \\
\mathrm{n}(\%)\end{array}$ & $80(74.8)$ & $285(46.4)$ & $<0.01$ \\
\hline TBSA percentage & $24.4 \pm 19.3$ & $20.2 \pm 18.0$ & $<0.01$ \\
\hline \multicolumn{4}{|l|}{ Severity $^{\star}, \mathrm{n}(\%)$} \\
\hline Minor & $35(32.7)$ & $238(38.8)$ & $<0.01$ \\
\hline Moderate & $21(19.6)$ & $127(20.7)$ & $<0.01$ \\
\hline Severe & $51(47.7)$ & $249(40.6)$ & $<0.01$ \\
\hline \multicolumn{4}{|l|}{ Burn grade, n (\%) } \\
\hline 2 & $8(7.5)$ & $126(20.5)$ & $<0.01$ \\
\hline 3 & $90(84.1)$ & $416(67.8)$ & $<0.01$ \\
\hline 4 & $9(8.4)$ & $72(11.7)$ & $<0.01$ \\
\hline $\begin{array}{l}\text { Admission } \\
\text { duration (days) }\end{array}$ & $75.0 \pm 45.3$ & $56.6 \pm 48.0$ & $<0.01$ \\
\hline $\begin{array}{l}\text { ICU } \\
\text { duration (days) }\end{array}$ & $19.3 \pm 24.1$ & $10.4 \pm 15.5$ & $<0.01$ \\
\hline Amputation, n (\%) & $19(17.8)$ & $61(9.9)$ & 0.04 \\
\hline $\begin{array}{l}\text { Escharotomy, n } \\
(\%)\end{array}$ & $33(30.8)$ & $93(15.1)$ & $<0.01$ \\
\hline Fasciotomy, n (\%) & $6(5.6)$ & $30(4.9)$ & 0.75 \\
\hline Skin graft, n (\%) & $87(81.3)$ & $447(72.8)$ & 0.03 \\
\hline \multicolumn{4}{|c|}{ Total Op count, n (\%) } \\
\hline 1 & $24(22.4)$ & 174 (28.3) & 0.58 \\
\hline 2 & $20(18.7)$ & $118(19.2)$ & 0.89 \\
\hline 3 & $16(15.0)$ & $76(12.4)$ & 0.78 \\
\hline$\geq 4$ & 34 (31.8) & $111(18.1)$ & 0.28 \\
\hline
\end{tabular}

*Severity adapted American Burn Association: hospital and prehospital resources for optimal care of patients with burn injury: guidelines for development and operation of burn centres. ${ }^{29}$ ICU, intensive care unit; Op, operation; TBSA, total body surface area.

correlated with WBC count and ICU stay duration. The relationship between TBSA and ICU stay duration increased in the control group $(\mathrm{r}=0.54, \mathrm{p}<0.01)$. However, in the cardiac complication group, the ICU duration was correlated with survival duration $(\mathrm{r}=0.57, \mathrm{p}<0.01)$, and TBSA was associated with WBC count elevation $(\mathrm{r}=0.45$, $\mathrm{p}<0.01$; online supplementary appendix figure S3).

\section{DISCUSSION}

In the present study, we reviewed 721 patients with electrical injuries who were treated at a single centre to investigate the manifestations of cardiac injury in adults with electrical injuries. Our study demonstrated that cardiac complications occurred in $14.8 \%$ of these individuals, 


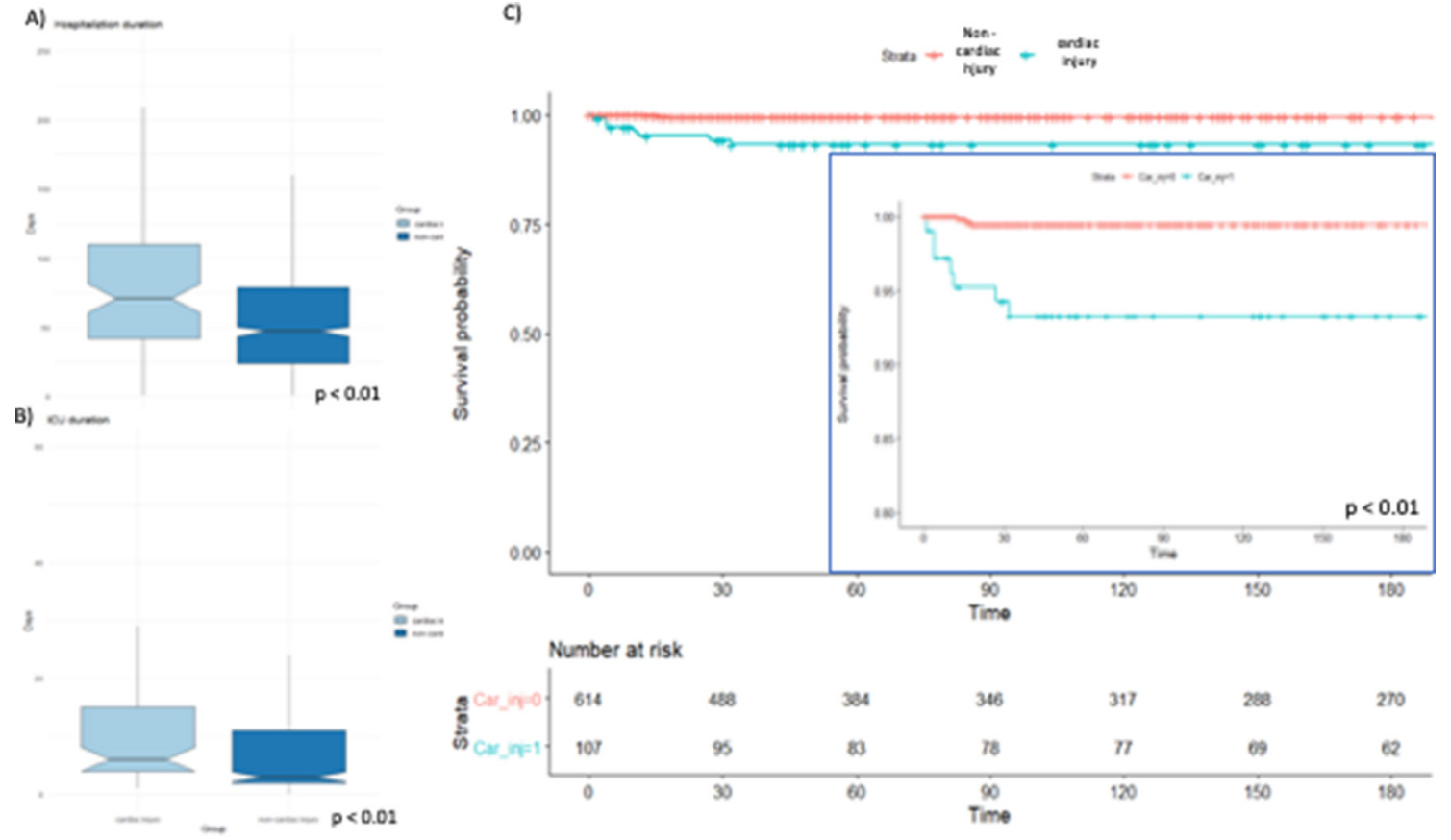

Figure 2 Group-wise admission characteristics. (A) Admission duration for the cardiac complication and control groups. (B) ICU duration for the cardiac complication and control groups. (C) Kaplan-Meier graph for the cardiac complication and control groups. ICU, intensive care unit.

a rate within the previously reported range $(14 \%-$ $54 \%) .{ }^{10}{ }^{15-17}$ Moreover, we examined the prognoses associated with these cases of post-burn cardiac complication. The rate, duration and ICU length of stay were all higher in the cardiac complication group compared with the control group. Ten of the 721 patients examined died from septic shock (seven patients), burn shock (two patients) and sudden cardiac arrest (one patient). All deaths occurred within the 32 days following admission, and no additional electrical injury patient died within the 6-month follow-up period (figure 2C, online supplementary appendix table S2). In addition, our study showed

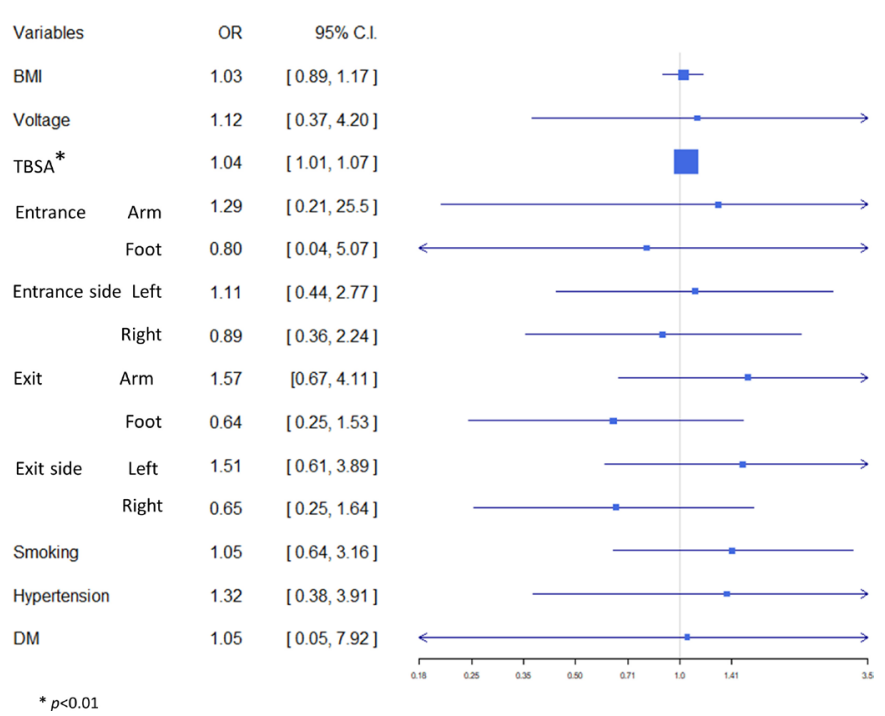

Figure 3 Association among patients' characteristics, injury characteristics and cardiac complications. BMI, body mass index; DM, diabetes mellitus; TBSA, total body surface area. that TBSA was related to cardiac complication with an OR of 1.04 (95\% CI 1.01 to 1.07 ; $\mathrm{p}<0.01$; figure 3 ).

Electrical injuries can result from various sources, such as both high-voltage and low-voltage sources, lightning and electrical arcs or sparks. ${ }^{8}$ Electrical injury-related symptoms are diverse and range from minor complications after small skin burns to life-threatening complications after more severe injury (described in detail in online supplementary appendix figure S4). ${ }^{134}$ Arrhythmia and myocardial tissue injuries are the two major cardiac complications associated with electrical shock. ${ }^{3}$ In previous studies, sinus tachycardia was known as the most common arrhythmic cardiac complication associated with electrical injuries. The mechanism by which electrically induced cardiac arrhythmias occur is not fully understood; however, endometrial biopsies reveal patchy myocardial fibrosis and increased numbers of $\mathrm{Na}^{+}$and $\mathrm{K}^{+}$pumps in affected tissue, as well as changes to membrane potential, which could trigger excess excitability after an injury. ${ }^{18}$ However, sinus tachycardia is associated with normal variation and various conditions, including haemodynamic instability, emotional change and infection. ${ }^{19-21}$ Therefore, a careful approach and criteria might be necessary for determining whether sinus tachycardia is related to electrical injury or some other conditions. Myocardial damage can be caused by the direct effects of electric current, which results in electrothermal conversion and electroporation. ${ }^{3}$ Usually, symptoms such as chest pain and chest discomfort are absent. Although we considered that elevated parameters of myocardial damage, such as CK-MB isoenzyme and Troponin levels, could indicate cardiac complications related to electrical injuries on the 
basis of several reports, more researches are needed. ${ }^{10} 1314$ Therefore, diagnosing myocardial damage as a complication of electrical injury still depends on an ECG. ${ }^{322}$

Almost all patients with electrical injuries are young and healthy, and some studies have reported that in cases of low-voltage injury but without a history of consciousness loss, initial cardiac arrest or an abnormal ECG at admission, the risk of arrhythmia is considerably low. ${ }^{7} 823-25$ Nevertheless, fatal arrhythmias could occur immediately following electrical shock and could lead to sudden cardiac death. ${ }^{42}$ Although there is no consensus on the most effective cardiac monitoring duration, most authors suggest monitoring for at least 24 hours after the injury or after arrhythmia resolution. ${ }^{13}$ Despite the lack of evidence for increased risk, patients with a prior history of heart disease should be carefully monitored. ${ }^{26}$ The reported mortality rates associated with electrical injuries also vary greatly but remain generally low. As in the present report, Sun et al reported an inpatient mortality rate of $1.6 \%$ in a Western area of China. ${ }^{2}$ Cheng et al reported a $6 \%$ mortality rate in Taiwan, and $\mathrm{Al}$ et al reported that mortality rate owing to electrical injuries in Turkey was $9.1 \%{ }^{527}$ In this study, mortality rate was $1.4 \%$ and, similar to Acosta et al.'s report, the most common cause of death was septic shock. ${ }^{28}$ We focused on the positive relationship between TBSA and WBC count why septic shock was the most common cause of death. Our study showed that all patients died by septic shock were in major burn injury (online supplementary appendix table S4). On that account, we assumed that cardiac complications can be accompanied with a large percentage of TBSA, which can more significantly impair the skin's ability to function as a barrier. Patients with cardiac complications could be vulnerable to inflammation and infection and may become septic easily, which can lead to death. Therefore, like patients with other types of burn, it may be important to treat infection and inflammation in patients with electrical injury, particularly in the patients with cardiac complications associated with electrical injury. Moreover, it is important that patients are treated well in the early phase of ICU care to prolong the survival duration in patients with cardiac complications related to electrical injury.

\section{Study limitations}

This present study has several limitations that warrant consideration. First, its single-centre, retrospective design poses some inherent limitations including selection bias and unknown confounding factors that could not be controlled for owing to which the generalisation of the results of this study to the broader population may be restricted. Second, we defined cardiac complications on the basis of electronic medical records and not direct examination. Consequently, we were unable to collect additional information on medical interventions or other adverse reactions to electrical injury during the follow-up period. Third, we excluded patients aged $<18$ years, despite the fact that electrical injuries to children often occur with a low voltage in the home. Therefore, had children been included, our outcomes likely would have been different.

\section{CONCLUSIONS}

This retrospective single-centre study is the first to report the incidence of electrical injury-related cardiac complications in South Korea. Here, we documented that resultant cardiac complications are associated with a poor prognosis, and TBSA is only significant relevant factor of cardiac complications. In addition, proper treatment for infection and inflammations at the early phase could be important in the patients with electrical injury, especially those with cardiac complications. In the future, prospective registry studies including patients of all ages are needed to more carefully examine how various complications are related to electrical injury, establish more accurate risk factors and detailed diagnostic criteria for electrical injury-related cardiac complications and determine its best possible treatment procedure.

\section{Author affiliations}

${ }^{1}$ Division of Cardiology, Department of Internal Medicine, Hangang Sacred Heart Hospital, Hallym University College of Medicine, Seoul, Republic of Korea

${ }^{2}$ Division of Cardiology, Department of Internal Medicine, Cardiovascular Center, Seoul National University Bundang Hospital, College of Medicine, Seoul National University, Seongnam, Republic of Korea

${ }^{3}$ Division of Cardiology, Department of Internal Medicine, Kangnam Sacred Heart Hospital, Hallym University College of Medicine, Seoul, Republic of Korea

${ }^{4}$ Department of Surgery and Critical Care, Burn Center, Hangang Sacred Heart Hospital, Hallym University College of Medicine, Seoul, Republic of Korea

Acknowledgements DH wish to acknowledge DY Kim for supporting him, and he also appreciate colleagues HK Lee, YH Moon, YR Shin and JH Lee in the Cardiovascular Center of Hangang Heart Sacred Hospital for helping with document collection.

Contributors $\mathrm{JHC}$ and DH conceptualised the study. DH and DK cleansed the data. $\mathrm{S}-\mathrm{HK}$ and DH analysed the data. C-HY and JRC reviewed the data analysis. JHC and $\mathrm{DH}$ wrote initial draft. DH, S-HK, C-HY and JRC reviewed the manuscript and interpreted the findings. JHC and DH revised the manuscript.

Funding This research was supported by Hallym University Research Fund 2017 (HURF-2017-84).

Competing interests None declared.

Patient consent for publication Obtained.

Provenance and peer review Not commissioned; externally peer reviewed.

Data sharing statement Data are available upon reasonable request.

Open access This is an open access article distributed in accordance with the Creative Commons Attribution Non Commercial (CC BY-NC 4.0) license, which permits others to distribute, remix, adapt, build upon this work non-commercially, and license their derivative works on different terms, provided the original work is properly cited, appropriate credit is given, any changes made indicated, and the use is non-commercial. See: http://creativecommons.org/licenses/by-nc/4.0/.

\section{REFERENCES}

1. Koumbourlis AC. Electrical injuries. Crit Care Med 2002;30:S424-S430.

2. Sun CF, Lv XX, Li YJ, et al. Epidemiological studies of electrical injuries in Shaanxi province of China: a retrospective report of 383 cases. Burns 2012;38:568-72. 
3. Waldmann V, Narayanan K, Combes N, et al. Electrical cardiac injuries: current concepts and management. Eur Heart $J$ 2018;39:1459-1465.

4. Spies C, Trohman RG. Narrative review: Electrocution and lifethreatening electrical injuries. Ann Intern Med 2006;145:531-7.

5. Al B, Aldemir M, Güloğlu C, et al. [Epidemiological characteristics of electrical injuries of patients applied to the emergency department]. Ulus Travma Acil Cerrahi Derg 2006;12:135-42.

6. Pawlik AM, Lampart A, Stephan FP, et al. Outcomes of electrical injuries in the emergency department: a 10-year retrospective study. Eur J Emerg Med 2016;23:448-54.

7. Fineschi V, Di Donato S, Mondillo S, et al. Electric shock: Cardiac effects relative to non fatal injuries and post-mortem findings in fatal cases. Int J Cardiol 2006;111:6-11.

8. Arnoldo BD, Purdue GF, Kowalske K, et al. Electrical injuries: a 20year review. J Burn Care Rehabil 2004;25:479-84.

9. Han TH, Kim JH, Yang MS, et al. A retrospective analysis of 19,157 burns patients: 18-year experience from Hallym Burn Center in Seoul, Korea. Burns 2005;31:465-70.

10. Chandra NC, Siu CO, Munster AM. Clinical predictors of myocardial damage after high voltage electrical injury. Crit Care Med 1990;18:293-7.

11. Arrowsmith J, Usgaocar RP, Dickson WA. Electrical injury and the frequency of cardiac complications. Burns 1997;23:576-8.

12. Searle J, Slagman A, Maaß W, et al. Cardiac monitoring in patients with electrical injuries. An analysis of 268 patients at the Charité Hospital. Dtsch Arztebl Int 2013;110:847-53.

13. Bose A, Chhabra CB, Chamania S, et al. Cardiac troponin I: A potent biomarker for myocardial damage assessment following high voltage electric burn. Indian J Plast Surg 2016;49:406-9.

14. Kinney TJ. Myocardial infarction following electrical injury. Ann Emerg Med 1982;11:622-5.

15. Solem L, Fischer RP, Strate RG. The natural history of electrical injury. J Trauma 1977;17:487-92.

16. Purdue GF, Hunt JL. Electrocardiographic monitoring after electrical injury: necessity or luxury. J Trauma 1986;26:166-7.
17. Housinger TA, Green L, Shahangian S, et al. A prospective study of myocardial damage in electrical injuries. J Trauma 1985;25:122-4.

18. Jensen PJ, Thomsen PE, Bagger JP, et al. Electrical injury causing ventricular arrhythmias. Br Heart J 1987;57:279-83.

19. Yusuf S, Camm AJ. Deciphering the sinus tachycardias. Clin Cardiol 2005;28:267-76.

20. Spodick $\mathrm{DH}$. Normal sinus heart rate: sinus tachycardia and sinus bradycardia redefined. Am Heart J 1992;124:1119-21.

21. Wung SF. Bradyarrhythmias: Clinical Presentation, Diagnosis, and Management. Crit Care Nurs Clin North Am 2016;28:297-308.

22. Priori SG, Blomstrom-Lundqvist C, Mazzanti A, et al. ESC Guidelines for the management of patients with ventricular arrhythmias and the prevention of sudden cardiac death: The Task Force for the Management of Patients with Ventricular Arrhythmias and the Prevention of Sudden Cardiac Death of the European Society of Cardiology (ESC). Endorsed by: Association for European Paediatric and Congenital Cardiology (AEPC). Eur Heart $J$ 2015;2015:2793-867.

23. Cunningham PA. The need for cardiac monitoring after electrical injury. Med J Aust 1991;154:765-6.

24. Fish RM. Electric injury, part III: cardiac monitoring indications, the pregnant patient, and lightning. J Emerg Med 2000;18:181-7.

25. Akkaș M, Hocagil $\mathrm{H}$, Ay $\mathrm{D}$, et al. Cardiac monitoring in patients with electrocution injury. Ulus Travma Acil Cerrahi Derg 2012;18:301-5.

26. Soar J, Perkins GD, Abbas G, et al. European Resuscitation Council Guidelines for Resuscitation 2010 Section 8. Cardiac arrest in special circumstances: Electrolyte abnormalities, poisoning, drowning, accidental hypothermia, hyperthermia, asthma, anaphylaxis, cardiac surgery, trauma, pregnancy, electrocution. Resuscitation 2010;81:1400-33.

27. Cheng PT, Lee CE, Yang JY. Electrical injury--clinical report of 67 cases. Changgeng Yi Xue Za Zhi 1994;17:220-5.

28. Acosta AS, Azarcon-Lim J, Ramirez AT. Survey of electrical burns in Philippine General Hospital. Ann N Y Acad Sci 1999;888:12-18.

29. American Burn Association. J Burn Care Rehabil 1990;11:98-104. 